\title{
Developmental Competence of Oocytes Recovered from Postmortem Ovaries of the Endangered Indian Blackbuck (Antilope cervicapra)
}

\author{
Brahmasani SAMBASIVA RAO ${ }^{1)}$, Yelisetti UMA MAHESH ${ }^{1)}$, \\ Uthanda Raman LAKSHMIKANTAN ${ }^{1)}$, Komjeti SUMAN ${ }^{1)}$, Katari VENU CHARAN ${ }^{1)}$ and \\ Sisinthy SHIVAJI' \\ 1) Laboratory for Conservation of Endangered Species (LaCONES), Centre for Cellular and Molecular Biology Annexe-I \\ (CSIR), Hyderabad 500 048, India
}

\begin{abstract}
The ability to rescue gametes from endangered or wildlife species and to subsequently produce viable embryos holds tremendous potential as a means to increase the population size of endangered or wildlife species. The objective of this study was to assess the meiotic and developmental competence of oocytes recovered from postmortem ovaries of the Indian blackbuck. Oocytes collected from the ovaries of dead blackbucks were allowed to mature in vitro and then tested for developmental potential by activation with ionomycin followed by treatment with 6 dimethylaminopurine. The average number of oocytes recovered per ovary was 10.9, and recovery of the oocytes did not depend on the presence or absence of the corpus luteum, on the side, size and weight of the ovaries or on the type of oocytes recovered. The proportion of good quality oocytes showing cumulus expansion and extrusion of the first polar body were $79.3 \%$ and $46.1 \%$ when cultured with gonadotropins. In vitro maturation studies indicated that the proportion of oocytes that reached MII stage was significantly higher when good quality oocytes (68\%) were used compared with fair quality oocytes $(48 \%)$ when cultured in the presence of gonadotropins. Furthermore, fifty eight percent of the in vitro matured oocytes cleaved, and thirteen percent of the cleaved oocytes developed into blastocysts. These findings suggest that the oocytes recovered from postmortem ovaries of the blackbuck can be utilized for production of embryos.
\end{abstract}

Key words: Blackbuck, In vitro maturation, Parthenogenetic activation

(J. Reprod. Dev. 56: 623-629, 2010)

$\mathbf{T}$ he blackbuck (Antilope cervicapra) is an endangered antelope native to the Indian subcontinent and has been listed as a Schedule I (endangered) animal under the Indian Wildlife Protection Act, 1972. The International Union for Conservation of Nature (IUCN) also lists the blackbuck as a near threatened animal [1].

Assisted reproductive technologies such as artificial insemination, in vitro maturation (IVM) of oocytes, in vitro fertilization (IVF), cryopreservation of oocytes and embryos, somatic cell nuclear transfer and embryo transfer are becoming increasingly important tools in the conservation and management of wild/endangered species [2-7]. However, the application of reproductive biotechnologies for the preservation of endangered mammalian species is limited by several factors $[8,9]$ such as the lack of availability of species-specific biological material required for a better understanding of the fundamental biology of the male and female gametes [10]. It is in this context that rescue of gametes from wild/ endangered animals that have died unexpectedly is a worthwhile research tool for understanding the fundamental physiology of the species concerned and also for development of species-specific

Received: April 26, 2010

Accepted: July 5, 2010

Published online in J-STAGE: August 11, 2010

(C2010 by the Society for Reproduction and Development

Correspondence: S Shivaji (e-mail: shivas@ccmb.res.in) protocols for application of new emerging assisted reproductive technologies in endangered species. In addition, production of competent oocytes by in vitro maturation (IVM) will positively facilitate IVF and somatic cell nuclear transfer (SCNT) technology for conservation of endangered animals.

Little research has been performed so far on collection and preservation of oocytes and on in vitro production of antelope embryos. To date, very few attempts have been made to explore the possibility of recovery, IVM and IVF of oocytes collected from ovaries of antelopes either from supervised culls or after death as reported earlier in klipspringer [11], blesbok [12, 13], addax antelope [14], blackbuck [15], black wildebeest [13], dorcas gazelle [16] and springbok $[13,17]$. To our knowledge, no information is available on oocyte recovery, morphology or IVM of oocytes in the blackbuck. It is in this context, the present study aims to present information on ovarian biometry, oocyte recovery, oocyte characteristics and IVM of oocytes collected from ovaries of the Indian blackbuck (Antilope cervicapra) postmortem.

\section{Materials and Methods}

\section{Preparation of media}

All the media, hormones, fetal bovine serum (FBS) and other chemicals used were purchased from Sigma Chemical, USA, and plasticware was obtained from Nunc, Denmark. HEPES buffered 
tissue culture medium 199 (TCM 199H) with 10\% FBS, penicillin $(100 \mathrm{IU} / \mathrm{ml})$ and streptomycin $(0.1 \mathrm{mg} / \mathrm{ml})$ was used for collection, washing and handling of oocytes. The washed oocytes were then incubated either in the control medium or gonadotropin-treatment medium. The control medium was prepared by supplementing bicarbonate buffered TCM 199 (TCM 199B) with 10\% FBS, 0.22 $\mathrm{mM}$ sodium pyruvate, penicillin $(100 \mathrm{IU} / \mathrm{ml})$ and streptomycin $(0.1$ $\mathrm{mg} / \mathrm{ml})$. The gonadotropin medium was prepared by supplementing the control medium with $10 \mu \mathrm{g} / \mathrm{ml}$ of follicle stimulating hormone (FSH) and $6 \mathrm{IU} / \mathrm{ml}$ luteinizing hormone (LH). All media were sterilized by filtration through $0.22 \mu \mathrm{m}$ filters (Millipore, USA) and equilibrated with $5 \%$ carbon dioxide in air in a humidified atmosphere at $38.5 \mathrm{C}$ for at least $2 \mathrm{~h}$ prior to use.

\section{Source of ovaries and oocyte collection}

Blackbucks were reared in captivity at the Nehru Zoological Park, Hyderabad, India. Female blackbucks were reared together in four adjoining indoor pens $(2.5 \times 2.5 \times 2.0 \mathrm{~m}$ each $)$ at night and were set free in a paddock $(13 \times 12 \mathrm{~m})$ during the day. Animals were exposed to the natural photoperiod and fed once in the morning with commercial cattle feed (Poshak Feeds, Hyderabad, India) supplemented with a mineral mixture (Agrimin; GlaxoSmithKline India, Mumbai, India). Green fodder was also provided twice a day, and the animals had free access to clean drinking water throughout the day. Ovaries from six female blackbucks aged 3-9 years that had died due to shock from sudden disturbances in the surroundings were collected 6-12 h after death at postmortem. The ovaries were placed individually in labelled, screw-top plastic tubes containing prewarmed (35 C) Dulbecco's phosphate buffered saline (D-PBS; Gibco, Invitrogen Corporation, USA) supplemented with $100 \mathrm{IU} / \mathrm{ml}$ penicillin and $0.1 \mathrm{mg} / \mathrm{ml}$ streptomycin and transported to the laboratory in a thermos flask maintained at 38.5 $\mathrm{C}$ within 1-2 h of collection. After reaching the laboratory, the ovaries were trimmed of adjacent fat and ligaments, and each ovary was examined for the presence of visible follicles and corpora lutea (CLs). Ovarian dimensions (length, width and thickness) were measured with Vernier callipers, and the weight was recorded. Each ovary was rinsed (2-3 sec) once in 70\% alcohol and thrice in prewarmed (37 C) D-PBS with antibiotics. Ovaries were placed into a 60 -mm culture dish containing $5 \mathrm{ml}$ of the oocyte handling medium supplemented with $25 \mathrm{IU} / \mathrm{ml}$ heparin (collection medium). Each ovary was processed individually. Incisions were made along the ovarian surface using a sterile surgical blade to release the cumulus-oocyte complexes (COCs) into a culture dish containing the oocyte collection medium. After slicing, each ovary was washed with the collection medium. Culture dishes were then kept undisturbed for $5 \mathrm{~min}$ to allow the oocytes to settle. The excess medium was then removed using a sterile syringe without disturbing the oocytes at the bottom of the culture dish. Thereafter, the culture dishes were examined for COCs under a stereozoom microscope (Nikon, Japan). Isolated COCs were then washed extensively in fresh droplets of handling medium and classified as good, fair or poor quality according to criteria used by Rao et al. [18]. Good COCs included oocytes with a homogeneous cytoplasm surrounded by more than three layers of compact cumulus cells. Fair COCs were similar to good COCs but were surrounded by at least one layer of cumulus cells. In the poor COCs, the oocyte cytoplasm was fragmented and had few or no cumulus cells. The poor COCs were not used.

\section{Measurement of oocyte diameter}

The average diameter of each oocyte with and without a zona (ooplasm) was measured at three different sites of the oocyte before and after in vitro maturation. Zona thickness was measured as the average thickness of the zona at five different sites of each oocyte. Oocyte diameter and zona thicknesses were determined using the XYClone software (Hamilton Thorne, USA).

\section{In vitro maturation of cumulus-oocyte complexes}

Good and fair quality COCs were selected for in vitro maturation. For this purpose, the selected COCs were washed extensively in fresh droplets of handling medium and then with the in vitro maturation medium. The washed COCs (in groups of 5-10) were then transferred into a 50- $\mu$ l droplet of either pre-equilibrated control or gonadotropin maturation medium and overlaid with equilibrated mineral oil. These droplets containing COCs were cultured in a incubator with $5 \% \mathrm{CO}_{2}$ under humidified air at $38.5 \mathrm{C}$ for $24 \mathrm{~h}$.

\section{Evaluation of oocytes following in vitro maturation}

At the end of the in vitro maturation period, COCs were examined for cumulus cell expansion. Subsequently, the oocytes were denuded of cumulus cells by repeatedly passing through a fire-polished narrow-bore glass pipette and examined for extrusion of the first polar body. Oocytes were also evaluated for nuclear status according to method used by Rao et al. [18]. Briefly, oocytes were washed thrice in microdroplets of handling medium containing Hoechst fluorescent dye ( $5 \mu \mathrm{g} / \mathrm{ml})$ and incubated for $15 \mathrm{~min}$ at 38.5 C. Subsequently, oocytes were examined using a fluorescence microscope (Olympus IX 70, Olympus Optical, Japan). The nuclear status of each oocyte was classified into one of five stages: (1) germinal vesicle (GV); (2) germinal vesicle breakdown (GVBD); (3) metaphase I (MI); (4) telophase I/metaphase II (MII); or (5) degenerate (Fig. 1). Oocytes exhibiting cumulus cell layer expansion, extrusion of the first polar body and presence of the MII stage were considered to be mature oocytes. Nuclear maturation was defined by the number of oocytes that had extruded the first polar body and the number of oocytes that had matured to the MII stage relative to the total number of oocytes that were cultured in vitro. Oocytes that were arrested at the GVBD stage or only progressed to MI were considered to be immature. Oocytes with fragmented cytoplasm or without chromatin were classified as degenerate.

\section{Activation of oocytes}

Oocytes that had extruded the first polar body were selected for activation. These oocytes were exposed to ionomycin $(5 \mu \mathrm{g} / \mathrm{ml})$ in the culture medium (TCM199B containing 15\% FBS) for 5 min, washed thoroughly in handling medium and then incubated in culture medium supplemented with 2 mM 6-dimethylaminopurine (6DMAP) for $5 \mathrm{~h}$ in a humidified atmosphere of $5 \% \mathrm{CO}_{2}$ in an incubator at $38.5 \mathrm{C}$. After completion of $5 \mathrm{~h}$ incubation in 6-DMAP, the 


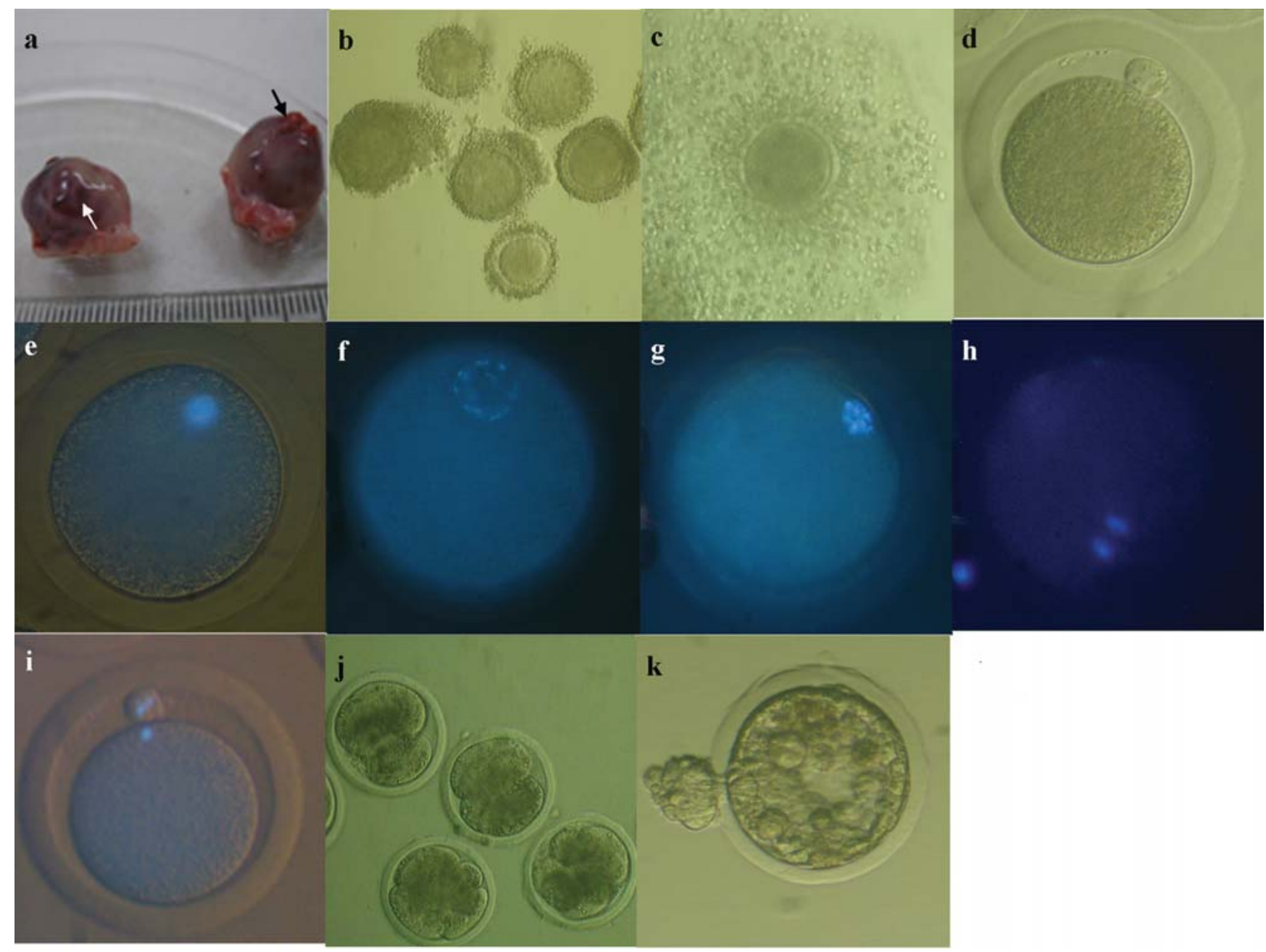

Fig. 1. In vitro maturation of blackbuck oocytes recovered from the ovaries (a) of dead Indian blackbucks. Corpora lutea (black arrow) and follicles (white arrow) were visible in the ovaries. Freshly collected culture grade oocytes (b) before IVM and various stages of oocyte maturation, such as the oocyte with cumulus cell expansion (c), oocyte with the first polar body (d), the germinal vesicle stage (e), germinal vesicle breakdown (f), metaphase I (g), telophase I (h) and metaphase II and the first polar body (i), are shown. In vitro development of 2-4 cell embryos (j) and a blastocyst (k) following parthenogenetic activation of IVM oocytes. The oocytes were stained with Hoechst 33342.

oocytes were washed thoroughly and cultured in culture medium for 7 days for further development.

\section{Statistical analysis}

The data were analyzed by using the SPSS version 16.0 software (SPSS, USA). Oocyte recovery and morphometry was analyzed by the Student's $t$-test. For in vitro maturation, the percentage data were arcsine transformed and analyzed by two-way analysis of variance followed by a least square difference (LSD) test. Differences in means were considered significant at $\mathrm{P}<0.05$.

\section{Results}

A total of 12 ovaries were collected from six female blackbucks postmortem. The average length, width, thickness and weight of the ovary were $1.43 \pm 0.10 \mathrm{~cm}, 1.09 \pm 0.08 \mathrm{~cm}, 0.75 \pm 0.06 \mathrm{~cm}$ and $0.75 \pm 0.12 \mathrm{~g}$, respectively. The mean number of visible follicles (>2 mm diameter) present on the ovaries was $5.33 \pm 0.84$ (range: 1 to 11$)$.

\section{Oocyte recovery}

A total of 131 oocytes were collected from 12 ovaries, out of which $45.8 \%$ were good $(n=60), 25.2 \%$ were fair $(n=33)$ and $29.0 \%$ were considered poor $(n=38)$. The good and fair quality oocytes ( $n$ $=93$ ) were used in all subsequent studies. The number of good and poor quality oocytes recovered per ovary did not depend on the size, weight, presence or absence of a CL or location of the ovary (left or right side; Table 1). However, the presence or absence of a CL and size of the ovary had a significant effect on the recovery of fair quality oocytes (Table 1). 
Table 1. Factors affecting oocyte recovery rate in blackbuck ovaries*

\begin{tabular}{|c|c|c|c|c|c|}
\hline \multirow[t]{2}{*}{ Attributes } & \multicolumn{5}{|c|}{ Number of oocytes recovered (Mean \pm SE) } \\
\hline & Total & Good & Fair & Poor & Culture grade \\
\hline \multicolumn{6}{|l|}{ I) Ovarian status } \\
\hline CL present $(n=3)$ & $10.0 \pm 1.0^{\mathrm{a}}$ & $6.0 \pm 1.0^{\mathrm{a}}$ & $1.3 \pm 0.3^{\mathrm{a}}$ & $2.7 \pm 0.3^{\mathrm{a}}$ & $7.3 \pm 1.2^{\mathrm{a}}$ \\
\hline CL absent $(n=9)$ & $11.2 \pm 1.7^{\mathrm{a}}$ & $4.7 \pm 0.8^{\mathrm{a}}$ & $3.2 \pm 0.8^{b}$ & $3.3 \pm 0.8^{\mathrm{a}}$ & $7.9 \pm 1.0^{\mathrm{a}}$ \\
\hline \multicolumn{6}{|l|}{ II) Side of ovary } \\
\hline Right (n=6) & $10.0 \pm 1.6^{\mathrm{a}}$ & $4.7 \pm 1.0^{\mathrm{a}}$ & $2.3 \pm 0.9^{\mathrm{a}}$ & $3.0 \pm 0.3^{\mathrm{a}}$ & $7.0 \pm 1.4^{\mathrm{a}}$ \\
\hline Left $(n=6)$ & $11.8 \pm 2.1^{\mathrm{a}}$ & $5.3 \pm 0.8^{\mathrm{a}}$ & $3.2 \pm 0.9^{\mathrm{a}}$ & $3.3 \pm 1.2^{\mathrm{a}}$ & $8.5 \pm 1.2^{\mathrm{a}}$ \\
\hline \multicolumn{6}{|l|}{ III) Ovarian size } \\
\hline$<8 \times 11 \times 15 \mathrm{~mm}^{3}(\mathrm{n}=6)$ & $12.5 \pm 1.0^{\mathrm{a}}$ & $4.7 \pm 0.8^{\mathrm{a}}$ & $4.2 \pm 0.9^{\mathrm{a}}$ & $3.7 \pm 1.2^{\mathrm{a}}$ & $8.8 \pm 1.2^{\mathrm{a}}$ \\
\hline$>8 \times 11 \times 15 \mathrm{~mm}^{3}(\mathrm{n}=6)$ & $9.3 \pm 1.5^{\mathrm{a}}$ & $5.3 \pm 1.1^{\mathrm{a}}$ & $1.3 \pm 0.3^{b}$ & $2.7 \pm 0.3^{\mathrm{a}}$ & $6.7 \pm 1.3^{\mathrm{a}}$ \\
\hline \multicolumn{6}{|l|}{ IV) Ovarian weight } \\
\hline Less than $750 \mathrm{mg}(\mathrm{n}=6)$ & $12.5 \pm 1.0^{\mathrm{a}}$ & $4.7 \pm 0.8^{\mathrm{a}}$ & $4.2 \pm 0.9^{\mathrm{a}}$ & $3.7 \pm 1.2^{\mathrm{a}}$ & $8.8 \pm 1.2^{\mathrm{a}}$ \\
\hline Greater than $750 \mathrm{mg}(\mathrm{n}=6)$ & $9.3 \pm 1.5^{\mathrm{a}}$ & $5.3 \pm 1.1^{\mathrm{a}}$ & $1.3 \pm 0.3^{b}$ & $2.7 \pm 0.3^{\mathrm{a}}$ & $6.7 \pm 1.3^{\mathrm{a}}$ \\
\hline
\end{tabular}

* Values are expressed as means \pm SEM. Means with different superscripts within a characteristic differ significantly $(\mathrm{P}<0.05)$.

Table 2. Micrometry of different grades of oocytes recovered from the ovaries of blackbucks*

\begin{tabular}{lcccc}
\hline Grade & \multicolumn{2}{c}{ Oocyte diameter $(\mu \mathrm{m})$} & Ooplasm diameter $(\mu \mathrm{m})$ & Zona thickness $(\mu \mathrm{m})$ \\
\cline { 2 - 3 } & With cumulus cells & Without cumulus cells & & \\
\hline Good & $222.6 \pm 1.8$ & $154.8 \pm 1.9^{\mathrm{a}}$ & $126.7 \pm 1.7^{\mathrm{a}}$ & $13.3 \pm 0.1^{\mathrm{a}}$ \\
Fair & $194.4 \pm 2.9$ & $147.5 \pm 2.6^{\mathrm{b}}$ & $118.4 \pm 2.5^{\mathrm{b}}$ & $13.3 \pm 0.2^{\mathrm{a}}$ \\
Poor & - & $156.9 \pm 2.5^{\mathrm{a}}$ & $127.1 \pm 2.5^{\mathrm{a}}$ & $13.9 \pm 0.6^{\mathrm{b}}$ \\
Overall & $212.2 \pm 1.7$ & $153.7 \pm 1.3$ & $124.8 \pm 1.3$ & $13.4 \pm 0.1$ \\
\hline
\end{tabular}

* Values are expressed as means \pm SEM. Means with different superscripts within a column differ significantly $(\mathrm{P}<0.05)$.

Table 3. Maturation of blackbuck oocytes after in vitro maturation in the presence or absence of gonadotropins*

\begin{tabular}{|c|c|c|c|c|c|c|c|c|c|}
\hline \multirow{2}{*}{$\begin{array}{l}\text { Oocyte } \\
\text { quality }\end{array}$} & \multirow{2}{*}{$\begin{array}{l}\text { Gonado- } \\
\text { tropins }\end{array}$} & \multirow{2}{*}{$\begin{array}{l}\text { Number of } \\
\text { oocytes }\end{array}$} & \multicolumn{2}{|c|}{ Morphological assessment } & \multicolumn{5}{|c|}{ Nuclear assessment } \\
\hline & & & CCE** & PBE** & $\mathrm{GV}^{* *}(\%)$ & $\mathrm{GVBD}^{* *}(\%)$ & $\mathrm{MI}^{* *}(\%)$ & TI/MII** (\%) & $\operatorname{Deg} * *(\%)$ \\
\hline Good & - & 15 & $60.4 \pm 6.2^{\mathrm{a}}$ & $33.3 \pm 5.8^{\mathrm{a}}$ & $6.2 \pm 3.1^{\mathrm{a}}$ & $20.8 \pm 7.2^{\mathrm{a}}$ & $33.3 \pm 5.8^{\mathrm{a}}$ & $39.6 \pm 6.25^{\mathrm{a}}$ & $0.00^{\mathrm{a}}$ \\
\hline Fair & - & 11 & $45.8 \pm 7.9^{\mathrm{a}}$ & $27.2 \pm 6.3^{\mathrm{a}}$ & $8.3 \pm 4.1^{\mathrm{a}}$ & $20.8 \pm 12.5^{\mathrm{a}}$ & $25.0 \pm 8.3^{\mathrm{a}}$ & $33.3 \pm 13.6^{\mathrm{a}}$ & $12.5 \pm 6.2^{\mathrm{a}}$ \\
\hline Good & + & 45 & $79.3 \pm 5.2^{b}$ & $46.1 \pm 3.3^{\mathrm{a}}$ & $3.4 \pm 2.1^{\mathrm{a}}$ & $9.6 \pm 1.6^{\mathrm{b}}$ & $15.1 \pm 2.7^{\mathrm{b}}$ & $68.0 \pm 5.2^{\mathrm{b}}$ & $3.6 \pm 3.5^{a}$ \\
\hline Fair & + & 22 & $65.6 \pm 7.5^{\mathrm{a}}$ & $38.8 \pm 6.8^{\mathrm{a}}$ & $8.5 \pm 5.1^{\mathrm{a}}$ & $13.9 \pm 5.2^{\mathrm{ab}}$ & $18.9 \pm 5.8^{\mathrm{ab}}$ & $48.0 \pm 6.9^{\mathrm{ab}}$ & $10.4 \pm 6.2^{\mathrm{a}}$ \\
\hline
\end{tabular}

*Values expressed as means \pm SEM. Means having different superscripts with in a column differ significantly $(\mathrm{P}<0.05)$. ${ }^{* *} \mathrm{CCE}$, cumulus cell expansion; PBE, polar body extrusion; GV, germinal vesicle; GVBD, germinal vesicle breakdown; MI, metaphase I; TI/MII, telophase I/metaphase II; Deg, degenerated.

\section{Oocyte morphometry}

Morphometric data such as oocyte diameter with and without cumulus cells, ooplasm diameter and zona thickness of the good, fair and poor quality oocytes are shown in Table 2 . The results indicated that the mean diameter of the oocytes with cumulus cells did not depend on the quality of the oocytes, but when the mean diameter of the oocytes without cumulus cells was compared between the different groups of oocytes, it was significantly higher in the good and poor quality compared with the fair quality oocytes. The highest mean diameter of the ooplasm in the poor and good quality oocytes was similar (about $127 \mu \mathrm{m}$ ) but significantly higher than that of the fair quality oocytes (118.46 $\pm 2.56 \mu \mathrm{m}$; Table 2). The zona thickness of the good and fair quality oocytes was not significantly different. However, the zona thickness of the poor quality oocytes was significantly higher than those of the good and fair quality oocytes (Table 2).

\section{In vitro maturation (IVM)}

In vitro maturation studies using good and fair quality indicated that the proportion of oocytes at different stages of development, such as those that exhibited cumulus cell expansion, polar body extrusion, presence of germinal vesicle and degeneration (Fig. 1), in both the control and gonadotropin treated groups were similar (Table 3). However, in the gonadotropin treated oocytes, the percentage of oocytes that exhibited cumulus cell expansion, germinal vesicle breakdown, Metaphase I and Telophase I and Metaphase II was higher $(\mathrm{P}<0.05)$ in the good quality oocytes compared with the good and fair quality oocytes of the control group. Furthermore, the good and fair quality oocytes of the gonadotropin treatment group differed significantly only with respect to the percentage of 
cumulus cell expansion (Table 3).

\section{Development of in vitro matured blackbuck oocytes after parthenogenetic activation}

A total of 38 oocytes that extruded the first polar body were subjected to activation with ionomycin followed by treatment with 6DMAP. Fifty eight percent of the oocytes cleaved (22/38), and thirteen percent of the cleaved oocytes developed to the blastocyst stage after 7 days.

\section{Discussion}

IVM followed by IVF and embryo transfer has resulted in live offspring only in selected wild species with a low success rate [10], and this has been attributed to problems related to the total absence or incomplete knowledge of the fundamental biology of male and female gametes and embryos [9]. Thus far, only one report has been published on in vitro development of blackbuck embryos derived from male and female gametes collected postmortem [15]. However, basic information regarding ovarian biometry, oocyte recovery, oocyte morphometry, IVM and activation of oocytes in the blackbuck has not yet been reported. In the present study, the average number of culture grade oocytes (fair and good quality) recovered per ovary was 7.75 , and this number is similar to the number of oocytes that were recovered from the dorcas gazelle [16] and white tailed deer [19] but higher than that observed in the blesbok [12] and springbok [17], in which 5 and 2.7 oocytes were recovered, respectively. Furthermore, it is also known that the number of oocytes recovered depends on the species, age, season and reproductive status of the donor animal [20,21]. The presence of a CL is also known to adversely affect the number of oocytes recovered in cattle [22], sheep [23], goats [21] and buffalo [24], and the cause has been attributed to the fact that progesterone secreted from the CL inhibits the growth of follicles and increases their atresia [25]. However, in bovine species, oocyte yield per ovary was higher for ovaries with a CL than without a CL [26, 27]. The reasons for this observed discrepancy are not clear. In the present study, oocyte recovery was not affected by the presence of a CL. The reason for this could be that both completely regressed CLs and regressing CLs were observed in the present study, and it is known that the progesterone levels secreted by a regressing CL are lower than those secreted by a functional CL. Therefore, it is likely that the low level of progesterone produced by the regressing CL may not be sufficient to inhibit growing follicles in the ovary. Indeed, this may be so, the case, and the observation that the proportion of good quality oocytes was higher in the CL group than in the CL absent group supports this hypothesis.

The large $\left(>8 \times 11 \times 15 \mathrm{~mm}^{3}\right)$ ovaries and ovaries $>750 \mathrm{mg}$ in weight yielded fewer oocytes than the ovaries that were small $(<8$ $\times 11 \times 15 \mathrm{~mm}^{3}$ ) and $<750 \mathrm{mg}$ in weight. This is in contrast to the ovaries of sheep, in which the mean number of oocytes recovered did not depend on the size of the ovaries [23].

The mean diameters of blackbuck oocytes with and without a zona (ooplasm) were found to be smaller than those of eland antelope [28] and Asian buffalo oocytes [29] aspirated from antral follicles. The mean thickness of the blackbuck zona pellucida was lower than that of the eland antelope [28] and higher than that of the goat [30]. It has been observed that the mean oocyte diameter increased from $96 \pm 0.3$ to $136 \pm 0.6 \mu \mathrm{m}$ as follicle size increased from 0.5 to $2-3 \mathrm{~mm}$ in the goat [31].

This is the first report of successful IVM and activation of oocytes collected from blackbuck ovaries after death using TCM 199 medium supplemented with pyruvate, gonadotropins and fetal calf serum. This modified TCM199 medium was used previously for IVM of oocytes of antelopes, such as the blesbok [12, 13], addax antelope [14], blackbuck [15], black wildebeest [13], dorcas gazelle [16], springbok [13, 17], eland and bongo [32]. Oocytes that were induced to mature in vitro (postmortem derived) developed to morulae/blastocysts following IVF in klipspringer [11], blackbuck [15] and springbok [17] antelopes. In the present study, the proportion of oocytes (68\%) that reached the MII stage after 24 $\mathrm{h}$ of culture was similar to that of the eland antelope (63\%) [32], higher than the proportions observed in other antelopes, such as the springbok (35\%) [13], blesbok (39\%) [13], dorcas gazelle (47\%) [16] and black wildebeest (52\%) [13], and lower than that the proportions observed in white tailed deer (77\%) [19] and bongo antelope (81\%) [32]. The low maturation rates may be due to the method of collection, since it has been recorded that slicing probably leads to the inclusion of non-competent oocytes from small diameter follicles [33], or to delay in collection of the ovaries from the animals after death. The time interval between animal death and collection of ovaries is important especially in wild animals because the onset of autolytic changes may cause degenerative changes in the follicles. In the present study, since the ovaries were collected due to the unexpected deaths of the blackbucks, the delay ranged between 6 to $12 \mathrm{~h}$ after death of the animals. Such delays could affect the ovaries and COCs that are recovered [34]. Other factors known to influence the success of in vitro maturation of oocytes include age, reproductive status, health of the oocyte donor, proper supplementation of the culture medium and quality of the oocytes [35, 36].

Concomitant with nuclear maturation during which the oocytes achieve the MII stage, the oocytes also undergo cytoplasmic maturation, which is a prerequisite for normal fertilization and development [37]. Granulosa and cumulus cells play a major role in oocyte growth, acquisition of meiotic competence and cytoplasmic maturation [38]. It has also been demonstrated that physical contact between the oocyte and cumulus cells is necessary for transfer of nutrients and factors essential for oocyte development $[24,39]$. This may be the reason why the blackbuck oocytes with homogenous cytoplasm surrounded by compact layers of cumulus cells in the present study had a significantly higher maturation rate.

In the present study, ionomycin followed by immediate exposure to 6-DMAP was used to induce oocyte activation. The only other report on activation of in vitro matured oocytes in antelopes was carried out using oocytes of the dorcas gazelle, and in that study, ethanol was used for activation [16]. Ionomycin followed by 6-DMAP has also been shown to be effective for inducing parthenogenesis of bovine [40], goat [41] and sheep [42] oocytes.

The differences in the potential of oocytes to develop into embryos may indicate differences with respect to cytoplasmic maturation, since oocyte competence to develop tends to increase with 
increasing follicle size [43, 44] and oocyte diameter [29, 45]. In the present study, the poor developmental rates after activation of in vitro matured oocytes may have been due to the variation in the size of the oocytes, since it has been reported that slicing probably leads to the inclusion of small diameter oocytes [33]. Although the oocytes reached the MII stage, only $13 \%$ of the cleaved oocytes developed to the blastocyst stage, and this may be due to improper cytoplasmic maturation. Miao et al. [46] demonstrated that the number of cells per blastocyst and blastocyst rates declined remarkably after in vitro maturation and activation of oocytes when the time interval between removal of ovaries and animal death increased. This may indeed be the case in the present study. Furthermore, it is also known that oocyte recovery, IVM and development to embryos depend on the species, age, season, reproductive status, nutrition and health of the donor animal [20, 21, 4753]. The results also demonstrate that oocytes recovered from blackbucks after sudden death of the animals possess competence to develop into embryos following in vitro maturation and activation.

Reproduction by cloning could be one of the methods used to increase the number of endangered/wild [54] or extinct species [55] in a population, for which competent oocytes for successful reprogramming of transferred nuclei is a must. The present study could thus be considered a step in this direction to generate oocytes competent for somatic cell nuclear transfer for production of cloned offspring of endangered animals.

\section{Acknowledgments}

This research was supported by grants from the Department of Biotechnology, Central Zoo Authority, and CSIR of the Government of India. The authors thank the Chief Wildlife Warden of Andhra Pradesh and the Director of Nehru Zoological Park, Hyderabad, for granting permission for collection of blackbuck ovaries.

\section{References}

1. International Union for the Conservation of Nature (IUCN). Available from $<$ www.iucnredlist.org > . (2010.03.30).

2. Pope CE. Embryo technology in conservation efforts for endangered felids. Theriogenology 2000; 53: 163-174.

3. Ptak G, Clinton M, Barboni B, Muzzeddu M, Cappai P, Tischner M, Loi P. Preservation of the wild European mouflon: the first example of genetic management using a complete program of reproductive biotechnologies. Biol Reprod 2002; 66: 796-801.

4. Shivaji S, Kholkute SD, Verma SK, Gaur A, Umapathy G, Singh A, Sontakke S, Shailaja K, Reddy A, Monika S, Sivaram V, Jyotsna B, Bala S, Ahmed MS, Bala A, Chandrashekar BVN, Gupta S, Prakash S, Singh L. Conservation of wild animals by assisted reproduction and molecular marker technology—a review. Indian J Exp Biol 2003; 41: 710-723.

5. Pukazhenthi BS, Wildt DE. Which reproductive technologies are most relevant to studying, managing and conserving wildlife? Reprod Fertil Dev 2004; 16: 33-46.

6. Amstislavsky S, Aalto J, Jarvinen M, Lindeberg H, Valtonen M, Zudova G, Ternovskaya Y. Transfer of European mink (Mustela lutreola) embryos into hybrid recipients. Theriogenology 2004; 62: 458-467.

7. Thundathil J, Whiteside D, Shea B, Ludbrook D, Elkin B, Nishi J. Preliminary assessment of reproductive technologies in wood bison (Bison bison athabascae): implications for preserving genetic diversity. Theriogenology 2007; 68: 93-99.

8. Pukazhenthi B, Comizzoli P, Travis AJ, Wildt DE. Applications of emerging technologies to the study of conservation of threatened and endangered species. Reprod Fertil Dev 2006; 18: 77-90.

9. Roldan ERS, Gomendio G, Garde JJ, Espeso G, Ledda S, Berlinguer F, Olmo AD, Soler AJ, Arregui L, Crespo C, Gonzalez R. Inbreeding and reproduction in endan- gered ungulates: preservation of genetic variation through the organization of genetic resource banks. Reprod Dom Anim 2006; 41 (Suppl 2): 82-92.

10. Andrabi SMH, Maxwell WMC. A review on reproductive biotechnologies for conservation of endangered mammalian species. Anim Reprod Sci 2007; 99: 223-243.

11. Raphael BL, Loskutoff NM, Huntress SL, Kraeme DC. Postmortem recovery, in vitro maturation and fertilization of kilispringer (Oreotragus oreotragus) ovarian oocytes. J Zoo and Wildlife Medicine 1991; 22: 115-118.

12. Winger $\mathbf{Q}$, Damiani $\mathbf{P}$, Loskutoff NM. The application of standard bovine protocols for the maturation and fertilization of blesbok (damaliscus dorcas phillipsi) oocytes using epididymal sperm cryopreserved in glycerol or dimethyl sulfoxide. Theriogenol ogy 1997; 47: 412 (abstract).

13. Brad AM, Spies T, Olivier F, Lane M, Gardner DK, Bartels P, Krisher RL. Timing of in vitro oocyte maturation in springbok (antidorcas marsupialis), black wildebeest (connechaetes gnu), blesbok (damaliscus dorcus phillipsi), and reedbuck (redunca arundinum). Reprod Fertil Dev 2004; 16: 223 (abstract).

14. Hall Woods ML, Asa CS, Bauman KL, Houston EW, Fischer MT, Junge RE, Krisher RL. In vitro embryo production in addax (Addax nasomaculatus), an endangered desert antelope. Biol Reprod 1999; 60: 178 (abstract).

15. Keller DL, Chapman SA, Westhusin ME, Drew ML, Kraemer DC. Production of invitro derived blackbuck antelope (antilope cervicapra.) embryos using standard bovine protocols. Theriogenology 1999; 51: 287 (abstract).

16. Roldan ERS, Berlinguer F, Succu S, Gonzalez R, Olmo AD, Espeso G, Gomendio M, Ledda S. In vitro maturation of oocytes from endangered dorcas gazelle (Gazella dorcas neglecta). Reprod Fertil Dev 2005; 18: 223 (abstract).

17. Krisher R, Auer A, Clark K, Emsweller K, Rogers S, Thomas K, Chatiza K, Bartels P. In vitro production of springbok (antidorcas marsupialis) embryos. Reprod Fertil Dev 2006; 19: 239 (abstract).

18. Rao BS, Naidu KS, Amarnath D, Vagdevi R, Rao AS, Brahmaiah KV, Rao VH. In vitro maturation of sheep oocytes in different media during breeding and non-breeding seasons. Small Rumin Res 2002; 43: 31-36.

19. Siriaroonrat B, Comizzoli P, Songsasen N, Monfort SL, Wildt DE, Pukazhenthi BS. Oocyte quality and estradiol supplementation affect in vitro maturation success in the white-tailed deer (Odocoileus virginianus). Theriogenology 2010; 73: 112-119.

20. Johnston LA, Donoghue M, Igo W, Simmons LG, Wildt DE, Rieffenberger J. Oocyte recovery and maturation in the American black bear (Ursus americanus): A model for endangered ursids. J Exp Zool 1994; 269: 53-61.

21. Islam MR, Khandoker MAMY, Afroz S, Rahman MGM, Khan RI. Qualitative and quantitative analysis of goat ovaries, follicles and oocytes in view of in vitro production of embryos. J Zhejiang Univ Sci B 2007; 8: 465-469.

22. Shioya $\mathbf{Y}$, Kuwayama M, Fukushima M, Iwasaki S. In vitro fertilization and cleavage capability of bovine follicular oocytes classified by cumulus cells and matured in vitro. Theriogenology 1988; 30: 489-494.

23. Wani NA,Wani GM, Khan MZ, Sidiqi MA. Effect of different factors on the recovery rate of oocytes for in vitro maturation and in vitro fertilisation procedures in sheep. Small Rumin Res 1999; 34: 71-76.

24. Amer HA, Hegab AO, Zaabal SM. Effects of ovarian morphology on oocyte quantity and quality, granulosa cells, in vitro maturation, and steroid hormone production in buffaloes. Anim Reprod 2008; 5: 55-62.

25. Hafez ESE. Folliculogenesis, egg maturation and ovulation. In: Reproduction in Farm Animals, Vol. 1. Lea and Febiger, Philadelphia 1993: 114-143.

26. Varisanga MD, Sumantri C, Murakami M, Fahrudin M, Suzuki T. Morphological classification of the ovaries in relation to the subsequent oocyte quality for IVF-produced bovine embryos. Theriogenology 1998; 50: 1015-1023.

27. Pierson RA, Ginther OJ. Reliability of diagnostic ultrasonography for identification and measurement of follicles and detecting the corpus luteum in heifers. Theriogenology 1987; 28: 929-936.

28. Wirtu G. Developing embryo technologies for the eland antelope (Taurotragus oryx). Dissertation, Louisiana State University, Baton Rouge, LA, USA 2004: 159

29. Raghu H, Nandi S, Reddy S. Follicle size and oocyte diameter in relation to developmental competence of buffalo oocytes in vitro. Reprod Fertil Dev 2002; 14: 55-61.

30. Bonia KK, Baishya N, Borgohain BN, Deka BC. Biometrics of ovarian oocytes and embryos of local goats of Assam. Indian J Anim Reprod 1998; 19: 43-45.

31. Crozet N, Dahirel M, Gall L. Meiotic competence of in vitro grown goat oocytes. J Reprod Fertil 2000; 118: 367-373.

32. Wirtu G, Pope CE, Paccamonti DL, Godke RA, Betsy DL. Ultrasonographic-guided retrieval and in vitro maturation of eland (Taurotragus oryx) and bongo (Tragelaphus eurycerus isaaci) antelope oocytes. Anim Reprod Sci 2009; 111: 160-172.

33. Rho GJ, Hahnel AC, Betteridge KJ. Comparison of oocyte maturation times and of three methods of spem preparation for their effects on the production of goat embryos in vitro. Theriogenology 2001; 56: 503-516.

34. Schroeder AC, Johnston D, Eppig JJ. Reversal of postmortem degeneration of mouse oocytes during meiotic maturation in vitro. J Exp Zool. 1991; 258: 240-245. 
35. Christensen M, Schmidt M, Hess D, Alak B. Oocyte nuclear maturation in vitro in the African (Loxodonta Africana) and Asian elephant (Elephas maximus). Biol Reprod 1993; 48: 88-95.

36. De Wit AAC, Wurth YA, Kruip TAM. Effect of ovarian phase and follicle quality on morphology and developmental capacity of the bovine-cumulus oocyte complex. $J$ Anim Sci 2000; 18: 1277-1283.

37. Thibault C, Szollosi D, Gerard M. Mammalian oocyte maturation. Reprod Nutr Develop 1987; 27: 865-896.

38. Crozet N, Huneau D, De Smedt V, Theron MC, Szollosi D, Torres S, Sevellec C. In vitro fertilization with normal development in sheep. Gamete Res 1987; 16: 159-170.

39. Albertini DF, Combelles CM, Benecchi E, Carabatsos MJ. Cellular basis for paracrine regulation of ovarian follicle development. Reproduction 2001; 121: 647-653.

40. Rho GJ, Wu B, Kawarsky S, Leibo SP, Betteridge KJ. Activation regimens to prepare bovine oocytes for intracytoplasmic sperm injection. Mol Reprod Dev 1998; 50: 485-492.

41. Ongeri EM, Bormann CL, Butler R, Mellican D, Gavin WG, Echelard Y, Krisher RL, Behboodi E. Parthenogenetic development of goat oocytes activated by different methods. Theriogenology 2001; 55: 1933-1945.

42. Loi P, Ledda S, Fulka J Jr, Cappai P, Moor RM. Development of parthenogenetic and cloned ovine embryos; effect of activation protocols. Biol Reprod 1998; 58: 1177-1187.

43. Pavlok A, Lucas Hahn A, Niemann H. Fertilization and developmental competence of bovine oocytes derived from different categories of antral follicles. Mol Reprod Dev 1992; 31: 63-67.

44. Hagemann LJ, Beaumont SE, Berg M, Donnison MJ, Ledgard A, Peterson AJ, Schurmann A, Tervit HR. Development during IVP of bovine oocytes from dissected follicles: interactive affects of estrous cycle stage, follicle size and atresia. Mol Reprod Dev 1999; 53: 451-458.

45. Otoi T, Yamamoto K, Koyama N, Tachikawa S, Suzuki T. Bovine oocyte diameter in relation to developmental competence. Theriogenology 1997; 48: 769-774.

46. Miao DQ, Ma SF, Liu XY, Sui HS, Zhang X, Qiao TW, Tan JH. Effects of delayed excision of oviducts/ovaries on mouse oocytes and embryos. Mol Reprod Dev 2007; 74 468-477.

47. Presicce GA, Jiang S, Simkin M, Zhang L, Looney CR, Godke RA, Yang XZ. Age and hormonal dependence of acquisition of oocyte competence for embryogenesis in prepubertal calves. Biol Reprod 1997; 56: 386-392.

48. Zheng P, Si W, Wang H, Zou R, Bavister BD, Ji W. Effect of age and breeding season on the developmental capacity of oocytes from unstimulated and follicle-stimulating hormone-stimulated rhesus monkeys. Biol Reprod 2001; 64: 1417-1421.

49. Saito H, Seino T, Kaneko T, Nakahara K, Toya M, Kurachi H. Endometriosis and oocyte quality. Gynecol Obstet Invest 2001; 53: 46-51.

50. Izquierdo D, Villamediana P, Lopez Bejar M, Paramio MT. Effect of in vitro and in vivo culture on embryo development from prepubertal goat IVM-IVF oocytes. Theriogenology 2002; 57: 1431-1441.

51. Koeman I, Keefer EL, Baldassarre H, Downey BR. Developmental competence of prepubertal and adult goat oocytes cultured in semi-defined media following laparoscopic recovery. Theriogenology 2003; 60: 879-889.

52. Santos JE, Cerri RL, Sartori R. Nutritional management of the donor cow. Theriogenology 2008; 69: 88-97.

53. Su L, Yang S, He X, Li X, Ma J, Wang Y, Presicce GA, Ji W. Effect of donor age on the developmental competence of bovine oocytes retrieved by ovum pick up. Reprod Dom Anim 2010; (in press). doi: 10.1111/j.1439-0531.2009.01349.x

54. Loi P, Ptak G, Barboni B, Fulka J, Cappai P, Clinton M. Genetic rescue of an endangered mammal by cross-species nuclear transfer using post-mortem somatic cells. Nat Biotech 2001; 19: 962-964.

55. Folch MJ, Cocero P, Chesné JL, Alabart V, Domínguez $\mathrm{Y}$, Cognié A, Roche A Fernández Árias JI, Martí P, Sánchez E, Echegoyen JF, Beckers A, Sánchez Bonastre $\mathbf{X}$, Vignon. First birth of an animal from an extinct subspecies (Capra pyrenaica pyrenaica) by cloning. Theriogenology 2009; 71: 1026-1034. 